\title{
Pleural lavage cytology as an independent prognostic factor in non-small-cell lung cancer patients with stage I disease and adenocarcinoma
}

\author{
DAISUKE HOKKA ${ }^{1}$, KAZUYA UCHINO $^{2}$, KENTA TANE $^{2}$, HIROYUKI OGAWA $^{1}$, \\ SINYA TANE ${ }^{1}$, YUGO TANAKA ${ }^{1}$, SHUNSUKE TAUCHI $^{1}$, WATARU NISHIO $^{2}$, \\ MASAHIRO YOSHIMURA ${ }^{2}$ and YOSHIMASA MANIWA ${ }^{1}$
}

\begin{abstract}
${ }^{1}$ Division of Thoracic Surgery, Department of Surgery, Kobe University Graduate School of Medicine, Kobe, Hyogo 650-0017; ${ }^{2}$ Department of Thoracic Surgery, Hyogo Cancer Center, Akashi, Hyogo 673-8558, Japan
\end{abstract}

Received May 22, 2014; Accepted September 5, 2014

DOI: $10.3892 / \mathrm{mco} .2014 .416$

\begin{abstract}
We previously reported that cancer cells may be detected through pleural lavage cytology (PLC). In this study, we sought to re-examine the prognostic significance of the PLC status based on an extended dataset with an additional follow-up period. Pleural lavage following thoracotomy was cytologically examined in 1,317 consecutive patients who were diagnosed with NSCLC between 1987 and 2004 at the Thoracic Surgery Units of Kobe University Graduate School of Medicine and Hyogo Cancer Center. Among the investigated patients, 46 exhibited positive cytological findings. The prognosis of these patients was significantly worse compared to that of patients without positive PLC. Of the 844 pathological stage I patients, 18 had a positive PLC status and their prognosis was significantly worse compared to that of patients with stage I disease without positive PLC. In conclusion, positive PLC findings were associated with a poor prognosis and this finding was significant for patients with stage I disease. These results suggest the need for PLC status evaluation during staging and treatment planning in patients with NSCLC.
\end{abstract}

\section{Introduction}

The cytological examination of pleural effusion is crucial for treatment planning and prognosis assessment for nonsmall-cell lung carcinoma (NSCLC). Indeed, positive cytology of the pleural effusion is considered to be a useful prognostic factor and is included as supplemental information in TNM staging (1). However, cancer cells may be present in the thoracic cavity even in the absence of pleural effusion.

Correspondence to: Dr Daisuke Hokka, Division of Thoracic Surgery, Department of Surgery, Kobe University Graduate School of Medicine, 7-5-2 Kusunoki-cho, Chuo-ku, Kobe 650-0017, Japan E-mail: daigoro1019@yahoo.co.jp

Key words: pleural lavage cytology, prognostic factor, non-small-cell lung cancer
We previously reported that cancer cells may be detected through pleural lavage cytology (PLC) at the time of thoracotomy in NSCLC patients without pleural effusion $(2,3)$ and evaluated the prognostic significance of positive cytology. Additionally, several other studies have suggested that PLC findings obtained during surgery are important prognostic indicators (4-13). However, the contribution of PLC to TNM staging has not yet been established. In the present study, we performed re-examinations and additional follow-up using our multi-institutional database, with the aim to assess the prognostic significance of PLC based on more extensive data.

\section{Patients and methods}

Patients. Between 1987 and 2004, PLC was performed in 2,043 NSCLC patients without pleural effusion or diffuse adhesions who had undergone primary tumor resection. The study sample included patients who underwent PLC at the Division of Thoracic Surgery, Kobe University (Kobe, Japan) or the Department of Thoracic Surgery, Hyogo Cancer Center (Akashi, Japan). In each of these cases, PLC was performed immediately following thoracotomy and prior to any manipulations in the thoracic cavity. We excluded all cases in which pleural effusion was present and could be aspirated using a syringe. Other exclusion criteria are listed in Fig. 1. The final study sample comprised 1,317 patients.

$P L C$. In all the patients, the pleural cavity was carefully washed with $100 \mathrm{ml}$ of physiological saline solution immediately following thoracotomy and prior to any further manipulation of the pulmonary parenchyma. To ensure a pure sample of desquamated cells, the surgeon avoided coming in contact with the pleural surface. Subsequently, the fluid was placed in a glass bottle with heparin and centrifuged at $1,500 \mathrm{x} g$ for $5 \mathrm{~min}$. The resulting sediment was stained using the Giemsa and Papanicolaou methods (14). The cytological examination results were classified as either negative or positive. Specifically, Papanicolaou classes I-III were considered to be negative, whereas classes IV and V were considered to be positive. 


\begin{tabular}{|c|c|c|}
\hline \multicolumn{2}{|c|}{ Primary lung cancer } & 2,043 \\
\hline & \multicolumn{2}{|l|}{ Induction therapy : 226} \\
\hline & Adhesion : 89 & \\
\hline & \multicolumn{2}{|c|}{ Multiple primary lung cancer : 76} \\
\hline & CT-guided biopsy $: 81$ & \\
\hline & Open thoracotomy : 62 & \\
\hline & Pathological stage IV : 51 & \\
\hline & Pneumonectomy : 41 & \\
\hline & Small-cell carcinoma : 18 & \\
\hline & Incomplete resection : 38 & \\
\hline & Dissemination : 25 & \\
\hline & Unknown data : 19 & \\
\hline Primar & y lung cancer & 1,317 \\
\hline
\end{tabular}

Figure 1. Flow chart of included cases, excluded cases and dropouts. The final study sample comprised 1,317 patients.

Preoperative evaluation and staging. Preoperative evaluations included a detailed patient history, physical examination, biochemical profile, chest radiography, bronchoscopy and computed tomography of the chest, brain and upper portion of the abdomen. Pathological staging was performed according to the International Staging System for Lung Cancer (1). Intraoperative staging was performed by dissecting intrapulmonary, hilar and mediastinal lymph node stations. The pathologists conducted careful postoperative examinations. The histological type of the tumor was determined according to the World Health Organization classification system (15). The therapeutic strategy, PLC technique and surgical procedure were strictly standardized for both institutes and a single surgeon performed all surgeries.

Statistical analysis. All the statistical analyses were performed using Stata software, version 10.1 (Stata Corp., College Station, USA). Baseline characteristics were reported as percentages for categorical variables and means \pm standard deviation (SD) for continuous variables. To investigate the association between PLC status and various clinicopathological parameters, we used the Fisher's exact test or the Student's unpaired t-test. For survival analyses, we used Kaplan-Meier estimates. The differences between survival curves were assessed using the log-rank test. Overall survival (OS) was defined as the time interval between the date of surgery and the date of death. Data were censored at the last visit. The Cox proportional hazards model was used to investigate the associations between OS and potential prognostic factors. All the variables that were found to be significantly associated with OS in the univariate analysis were included in the multivariate Cox analysis. Values of $\mathrm{P}<0.05$ were considered to indicate statistically significant differences in all the analyses.

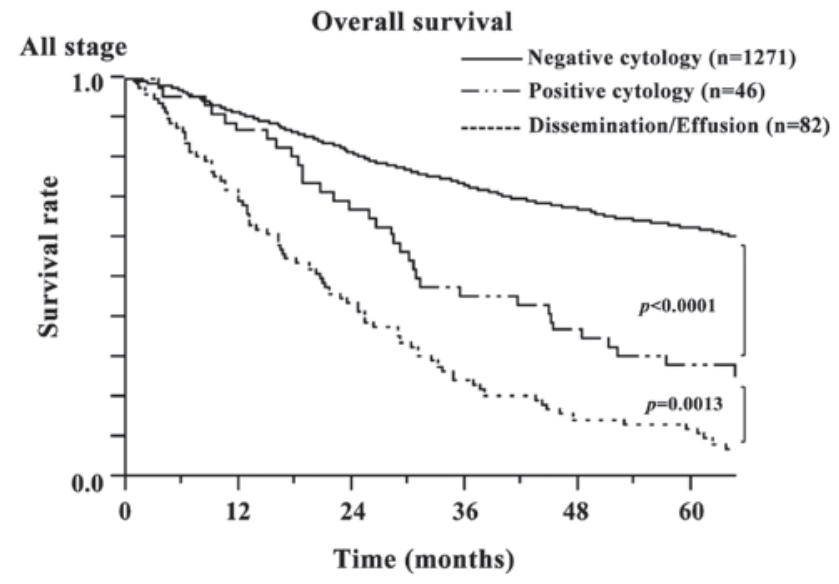

Figure 2. Kaplan-Meier plot of the overall survival rate in 1,317 patients with NSCLC and its association with the PLC status in all-stage patients. The P-value was determined using the log-rank test.

\section{Results}

PLC results. PLC immediately following thoracotomy was positive in 46 of the 1,317 cases (3.5\%). Patients with positive cytological findings had a significantly worse prognosis compared to those with negative cytological findings (5-year survival rate: 28 vs. $61 \%$, respectively; $\mathrm{P}<0.0001$; Fig. 2 ). The median follow-up was 5.7 years (range, 1.0-13.1 years). Patients with positive cytological findings had a better prognosis compared to those with dissemination/effusion (5-year survival rate: 28 vs. $12 \%$, respectively; $\mathrm{P}=0.0013$; Fig. 2).

Association of PLC status and clinicopathological characteristics. Table I presents the associations between the PLC status and various clinicopathological characteristics at the time of surgery. Positive cytology was significantly associated with female gender $(\mathrm{P}=0.0065)$ and adenocarcinoma histology $(\mathrm{P}<0.0001)$. Pathological stage (stages II and III; $\mathrm{P}<0.0001)$, pleural invasion ( $\mathrm{P} 2$ and $\mathrm{P} 3$; $\mathrm{P}<0.0001)$, lymphatic invasion $(\mathrm{Ly}+; \mathrm{P}<0.0001)$ and vascular invasion $(\mathrm{V}+; \mathrm{P}<0.0001)$ were each significantly associated with positive PLC findings. All the pathological classifications were performed according to the criteria of the International Staging System for Lung Cancer (1).

Prognostic value of clinicopathological characteristics. We additionally investigated the prognostic value of clinicopathological characteristics. All the variables that were found to be significantly associated with OS in the univariate analysis (log-rank test; data not shown) were entered into a Cox proportional hazards multivariate analysis. Of note, the PLC status was among these significant associations. The multivariate analysis revealed that gender (male), age ( $\geq 65$ years), preoperative serum carcinoembryonic antigen $(>5.0 \mathrm{ng} / \mathrm{ml})$, pathological stage (stages II and III), tumor size ( $>30 \mathrm{~mm}$ in diameter), pleural invasion (+), lymphatic invasion (Ly+), vascular invasion ( $\mathrm{V}+)$ and PLC status were independent, statistically significant predictors of OS (Table II).

Of the 844 stage I cases, $18(2.1 \%)$ were classified as PLC-positive (Fig. 3). Among the stage I cases, a log-rank test revealed that the PLC-positive group had a significantly worse OS compared to the PLC-negative group ( $\mathrm{P}<0.0001$; Fig. 3). 
Table I. Associations between pleural lavage cytology status and various clinicopathological characteristics at the time of surgery.

\begin{tabular}{|c|c|c|c|c|c|}
\hline \multirow[b]{2}{*}{ Characteristics } & \multicolumn{3}{|c|}{ Pleural lavage cytology } & \multirow[b]{2}{*}{$\begin{array}{c}\text { Total } \\
(\mathrm{n}=1,317)\end{array}$} & \multirow[b]{2}{*}{ P-value } \\
\hline & $\begin{array}{r}\text { Positive } \\
(\mathrm{n}=\end{array}$ & $\begin{array}{l}\text {, no. }(\%) \\
=46)\end{array}$ & $\begin{array}{l}\text { Negative, no. } \\
\quad(n=1,271)\end{array}$ & & \\
\hline Age (years) & & & & & 0.8074 \\
\hline$<65$ & 19 & $(3.4)$ & 548 & 567 & \\
\hline$\geq 65$ & 27 & $(3.6)$ & 723 & 750 & \\
\hline Gender & & & & & 0.0065 \\
\hline Male & 23 & $(2.6)$ & 877 & 900 & \\
\hline Female & 23 & $(5.5)$ & 394 & 417 & \\
\hline CEA (ng/ml) & & & & & 0.0561 \\
\hline$\leq 5.0$ & 23 & $(2.8)$ & 811 & 834 & \\
\hline$>5.0$ & 23 & $(4.8)$ & 460 & 483 & \\
\hline Procedure & & & & & 0.9516 \\
\hline Limited resection & 11 & $(3.4)$ & 309 & 320 & \\
\hline Lobectomy & 35 & $(3.5)$ & 962 & 997 & \\
\hline Pathological stage & & & & & $<0.0001$ \\
\hline I & 18 & $(2.1)$ & 826 & 844 & \\
\hline II & 12 & $(5.2)$ & 219 & 231 & \\
\hline III & 16 & $(6.6)$ & 226 & 242 & \\
\hline Tumor size (mm) & & & & & 0.0870 \\
\hline$\leq 30$ & 19 & $(2.7)$ & 688 & 707 & \\
\hline$>30$ & 27 & $(4.4)$ & 583 & 610 & \\
\hline Histology & & & & & $<0.0001$ \\
\hline Adenocarcinoma & 43 & $(5.2)$ & 785 & 828 & \\
\hline Squamous cell carcinoma & 3 & $(0.7)$ & 400 & 403 & \\
\hline Other $^{\mathrm{a}}$ & 0 & & 86 & 86 & \\
\hline Pleural involvement & & & & & $<0.0001$ \\
\hline $\mathrm{P} 0$ & 3 & $(0.4)$ & 711 & 714 & \\
\hline $\mathrm{P} 1$ & 12 & $(3.0)$ & 382 & 394 & \\
\hline $\mathrm{P} 2$ & 18 & $(24.7)$ & 55 & 73 & \\
\hline $\mathrm{P} 3$ & 13 & $(9.6)$ & 123 & 136 & \\
\hline Lymphatic invasion & & & & & $<0.0001$ \\
\hline Negative & 17 & $(2.0)$ & 843 & 860 & \\
\hline Positive & 29 & $(6.3)$ & 428 & 457 & \\
\hline Vascular invasion & & & & & $<0.0001$ \\
\hline Negative & 15 & $(2.0)$ & 725 & 740 & \\
\hline Positive & 31 & $(5.4)$ & 546 & 577 & \\
\hline
\end{tabular}

${ }^{a}$ Adenosquamous carcinoma, large-cell carcinoma, pleomorphic carcinoma, large-cell neuroendocrine carcinoma, carcinoid tumor.

Table III presents the recurrence pattern in the 46 PLC-positive cases. Of those patients, 33 (71.7\%) exhibited disease recurrence. The local and distant recurrence rates at 5 years were 34.8 and $36.9 \%$, respectively.

\section{Discussion}

In 1958, Spjut et al (16) were the first to publish a report on cytological examination for cancer cells in pleural cavity washings at the time of thoracotomy. Eagan et al (17) and
Okumura et al (18) later analyzed the clinical significance of this procedure and indicated its prognostic value. We developed our PLC procedure (described in Patients and methods) in the 1980s. Since then, our continuous follow-up survey has demonstrated the prognostic significance of the PLC status $(2,3)$. In the present study, we conducted an analysis of the most recent data (including 3 years of additional follow-up and 317 new patients), with the aim to provide a more detailed understanding of the clinical significance of the PLC status in NSCLC patients. 
Table II. Multivariate analysis of overall survival.

\begin{tabular}{|c|c|c|c|c|}
\hline Factors & Favorable & Unfavorable & Hazard ratio $(95 \% \mathrm{CI})$ & $\mathrm{P}$-value \\
\hline Age (years) & $<65$ & $\geq 65$ & $1.788 \quad(1.481-2.170)$ & $<0.0001$ \\
\hline Gender & Female & Male & $1.612(1.377-1.891)$ & $<0.0001$ \\
\hline CEA (ng/ml) & $\leq 5.0$ & $>5.0$ & $1.452 \quad(1.247-1.691)$ & $<0.0001$ \\
\hline Procedure & Lobectomy & Limited resection & $1.028 \quad(0.838-1.255)$ & 0.7877 \\
\hline Pathological stage & I & II/III & $2.212(1.878-2.606)$ & $<0.0001$ \\
\hline Tumor size (mm) & $\leq 30$ & $>30$ & 1.349 (1.140-1.598) & 0.0005 \\
\hline Histology & $\mathrm{AD}$ & Non-AD & $1.144 \quad(0.968-1.351)$ & 0.1135 \\
\hline Pleural involvement & Negative & Positive & $1.206(1.027-1.416)$ & 0.0222 \\
\hline Lymphatic invasion & Negative & Positive & $1.332(1.130-1.570)$ & 0.0007 \\
\hline Vascular invasion & Negative & Positive & $1.259(1.072-1.479)$ & 0.0054 \\
\hline Pleural lavage cytology & Negative & Positive & $1.535(1.065-2.149)$ & 0.0226 \\
\hline
\end{tabular}

95\% CI, 95\% confidence interval; AD, adenocarcinoma.

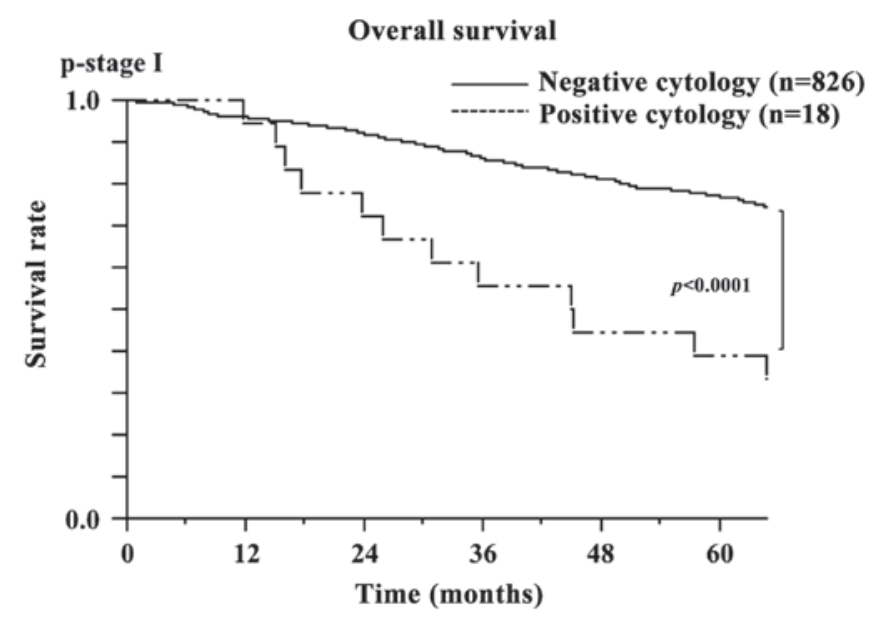

Figure 3. Kaplan-Meier plot of the overall survival rate in 844 cases with NSCLC and its relationship to the PLC status in stage I patients. P-value was determined using the log-rank test.

PLC immediately following thoracotomy yielded positive results in 46 of the 1,317 patients $(3.5 \%)$. This percentage is similar to our previous findings $(2,3)$ and is also similar to the findings reported by other studies (4-13). A 5-year survival rate of $28 \%$ was observed among the patients who were found to be PLC-positive. The prognosis of such patients remains poor, similar to our earlier findings. We previously compared the survival of PLC-positive patients to that of patients who had positive pleural effusion findings at the time of lung resection and found no significant survival differences between these two groups (2). The results of the present study also suggest that a positive PLC status may be clinically synonymous with malignant pleural effusion.

In the present study, we also investigated the associations between PLC status and clinicopathological characteristics at the time of surgery. Positive cytology was found to be significantly associated with female gender and adenocarcinoma histology. In 43 of the 46 PLC-positive cases, the histological diagnosis was adenocarcinoma. Conversely, among all adeno-
Table III. Recurrence pattern in PLC positive.

\begin{tabular}{lcccc}
\hline & \multicolumn{3}{c}{ Stages } \\
\cline { 2 - 4 } $\begin{array}{l}\text { Recurrence } \\
\text { pattern }\end{array}$ & $\begin{array}{c}\text { I } \\
(\mathrm{n}=18)\end{array}$ & $\begin{array}{c}\text { II } \\
(\mathrm{n}=12)\end{array}$ & $\begin{array}{c}\text { III } \\
(\mathrm{n}=16)\end{array}$ & $\begin{array}{c}\text { Total } \\
(\mathrm{n}=46)\end{array}$ \\
\hline No recurrence & 6 & 3 & 1 & 10 \\
Local & 6 & 4 & 6 & 16 \\
Distant & 6 & 3 & 8 & 17 \\
Unknown & 0 & 2 & 1 & 3 \\
\hline
\end{tabular}

carcinoma patients, $5.2 \%$ had a positive PLC status. A positive PLC status and adenocarcinoma are more common among patients with NSCLC. Consequently, the PLC procedure may become indispensable for the precise assessment of the clinical outcomes of NSCLC in the near future. Additionally, pleural, lymphatic and vascular invasion were found to be significantly associated with positive PLC findings. Accordingly, we recommend that the PLC status becomes a feature of NSCLC classification as part of TNM staging.

Cytological examination of the fluid has always been recommended for NSCLC cases with pleural effusion. Indeed, the cytological examination results are reflected in the staging of the disease. However, the PLC status has not yet been incorporated in the latest edition of TNM staging for lung cancer (1). Pleural effusion is not an indispensable finding in terms of cancer cell dissemination into the thoracic cavity. Indeed, pleural dissemination is occasionally detected despite a lack of pleural effusion. Therefore, we recommend that PLC is universally performed at the time of thoracotomy to evaluate the spread of NSCLC cells into the thoracic cavity.

A positive PLC status was detected in 18 of the 844 stage I cases $(2.1 \%)$. The deviation between survival curves (PLC-positive vs. PLC-negative) was significant among stage I patients. A positive PLC status was associated with a high 
recurrence rate and this finding was significant for patients with stage I disease. These results suggest that the PLC procedure may be crucial in treatment planning for earlier-stage patients. More specifically, PLC findings may enable a more optimal selection of patients who may benefit from postoperative adjuvant therapy, possibly achieving more favorable outcomes following surgical resection in stage I NSCLC patients.

In conclusion, the PLC findings were positive in $3.5 \%$ of patients with surgically resected NSCLC and the rate of positive findings was higher among female patients and among patients with adenocarcinoma. Additionally, a positive PLC status was identified as an independent prognostic factor for OS. Together with previous findings, our results indicate that PLC status may be of value during staging and treatment planning in patients with NSCLC. The PLC procedure may contribute to the selection and adaptation of adjuvant therapy for patients with NSCLC, particularly those with early-stage disease.

\section{References}

1. Goldstraw P, Crowley J, Chansky K, et al; International Association for the Study of Lung Cancer International Staging Committee; Participating Institutions: The IASLC Lung Cancer Staging Project: proposals for the revision of the TNM stage groupings in the forthcoming (seventh) edition of the TNM Classification of Malignant Tumours. J Thorac Oncol 2: 706-714, 2007.

2. Okada M, Tsubota N, Yoshimura M, Miyamoto Y and Maniwa Y: Role of pleural lavage cytology before resection for primary lung carcinoma. Ann Surg 229: 579-584, 1999.

3. Okada M, Sakamoto R, Nishio W, Uchino K, Tsuboshima K and Tsubota N: Pleural lavage cytology in non-small cell lung cancer: lessons from 1000 consecutive resections. J Thorac Cardiovasc Surg 126: 1911-1915, 2003.

4. Kjellberg SI, Dresler CM and Goldberg M: Pleural cytologies in lung cancer without pleural effusions. Ann Thorac Surg 64: 941-944, 1997.

5. Riquet M, Badoual C, Barthes FP, et al: Visceral pleural invasion and pleural lavage tumor cytology by lung cancer: a prospective appraisal. Ann Thorac Surg 75: 353-355, 2003.
6. Lim E, Ali A, Theodorou P, Nicholson AG, Ladas G and Goldstraw P: Intraoperative pleural lavage cytology is a independent prognostic indicator for staging non-small cell lung cancer. J Thoracic Cardiovasc Surg 127: 1113-1118, 2004.

7. Tomita M, Shimizu T, Matsuzaki Y, Hara M, Ayabe T and Onitsuka T: Prognostic significance of carcinoembryonic antigen level in pleural lavage fluid for patients with lung adenocarcinoma. Ann Thorac Surg 80: 276-281, 2005.

8. Satoh Y, Hoshi R, Ishikawa Y, Horai T, Okumura S and Nakagawa K: Recurrence patterns in patients with early stage non-small cell lung cancers undergoing positive pleural lavage cytology. Ann Thorac Surg 83: 197-203, 2007.

9. Nakagawa T, Okumura N, Kokado Y, Miyoshi K, Matsuoka T and Kameyama K: Clinical relevance of intraoperative pleural lavage cytology in non-small cell lung cancer. Ann Thorac Surg 83: 204-208, 2007.

10. Kawachi R, Nakazato Y, Masui K, Takei H, Koshi-ishi Y and Goya T: Clinical significance of pleural lavage cytology for non-small cell lung cancer: is surgical resection valid for patients with positive pleural lavage cytology? Interact Cardiovasc Thorac Surg 9: 265-268, 2009.

11. Nakamura T, Suzuki K, Mochizuki T, et al: Prognostic significance and possibility in guiding adjuvant therapy of the pleural lavage cytology in patients with non-small cell lung cancer. Interact Cardiovasc Thorac Surg 8: 321-324, 2009.

12. Lim E, Clough R, Goldstraw P, et al; International Pleural Lavage Cytology Collaborators: Impact of positive pleural lavage cytology on survival in patients having lung resection for nonsmall-cell lung cancer: An international individual patient data meta-analysis. J Thorac Cardiovasc Surg 139: 1441-1446, 2010.

13. Kaneda M, Yokoi K, Ito S, et al: The value of pleural lavage cytology examined during surgery for primary lung cancer. Eur J Cardiothorac Surg 41: 1335-1341, 2012.

14. Dettmeyer R: Forensic Histopathology. Springer-Verlang, Berlin, pp17-35, 2011.

15. Travis WD, Brambilla E, Müller-Hermelink HK and Harris CC (eds): Pathology and genetics of tumours of the lung, pleura, thymus and heart. In: World Health Organization Classification of Tumors. IARC Press, Lyon, pp10-124, 2004.

16. Spjut HJ, Hendrix VJ, Ramirez GA and Roper CL: Carcinoma cells in pleural cavity washings. Cancer 11: 1222-1225, 1958.

17. Eagan RT, Bernatz PE, Payne WS, et al: Pleural lavage after pulmonary resection for bronchogenic carcinoma. J Thorac Cardiovasc Surg 88: 1000-1003, 1984.

18. Okumura M, Ohshima S, Kotake Y, Morino H, Kikui M and Yasumitsu T: Intraoperative pleural lavage cytology in lung cancer patients. Ann Thorac Surg 51: 599-604, 1991. 